\title{
“KARYSTÍA LÍTHOS”: A TIMELESS STRUCTURAL ORNAMENTAL STONE
}

\author{
Laskaridis K. ${ }^{1}$ and Patronis M. ${ }^{1}$ \\ ${ }^{1}$ Institute of Geology and Mineral Exploration, Department of Economic Geology, \\ LITHOSLaboratory, 13766 Atnens, Greece, laskaridis@igme.gr, patronis@igme.gr
}

\begin{abstract}
Karystía Lithos (= Stone of Karystos) is a widely used structural material since archaic times. It has been used in various constructions, considered to date before 700 BC or before the Trojan War or even as early as the Neolithic Age. The term "Karystía Lithos", mentioned by Strabo, Pliny et al., includes cipollino marble, slates etc. Their main mineralogical constituent is calcite and their colour depends on the secondary and accessory minerals. This paper examines the timelessness of Karystia Lithos, focusing on the determination of its physical - mechanical and aesthetic characteristics. The natural stone properties are classified into those characterizing the material, and those determining the suitability of the stone for various special uses. Those properties were determined according to Standard EN 12326-2 "Slate and stone products for discontinuous roofing and cladding - Part 2: Methods of test". The results were statistically analyzed, in order to draw relevant practical conclusions. The physical - mechanical properties of Karystía Lithos, on which its endurance through time and under mechanical stresses is depending, and its aesthetics, render it a widely applied ornamental stone to-date.
\end{abstract}

Key words: Karystía Lithos, "Karystos Schists”, physical - mechanical properties, EN 12326-2, statistical analysis.

\section{Introduction}

Karystía Líthos (= Stone of Karystos) is a widely used structural material since archaic times. It has been employed in the construction of columns, monuments and other buildings of colossal ("cyclopean") dimensions, used for decorative, ritualistic or other practical purposes. It is considered that those constructions date before $700 \mathrm{BC}$ or before the Trojan War or even as early as the Neolithic Age.

The term "Karystía Líthos" - as it is mentioned by Strabo, Pliny et al. - refers to cipollino marble, slates etc. These stones are still quarried in the southern part of Euboea Island, under the commercial name "Karystos Schists".

The objective of this paper is to examine the reasons for the timelessness of Karystía Líthos, focusing on the determination of its physical - mechanical properties and its aesthetic characteristics.

Those features were determined according to the test methods specified in Standard EN 12326-2 "Slate and stone products for discontinuous roofing and cladding - Part 2: Methods of test".

All tests were carried out in the accredited Ornamental Stones Quality Control Laboratory of I.G.M.E., "LITHOS". The relevant results were evaluated via statistical analysis methods. 


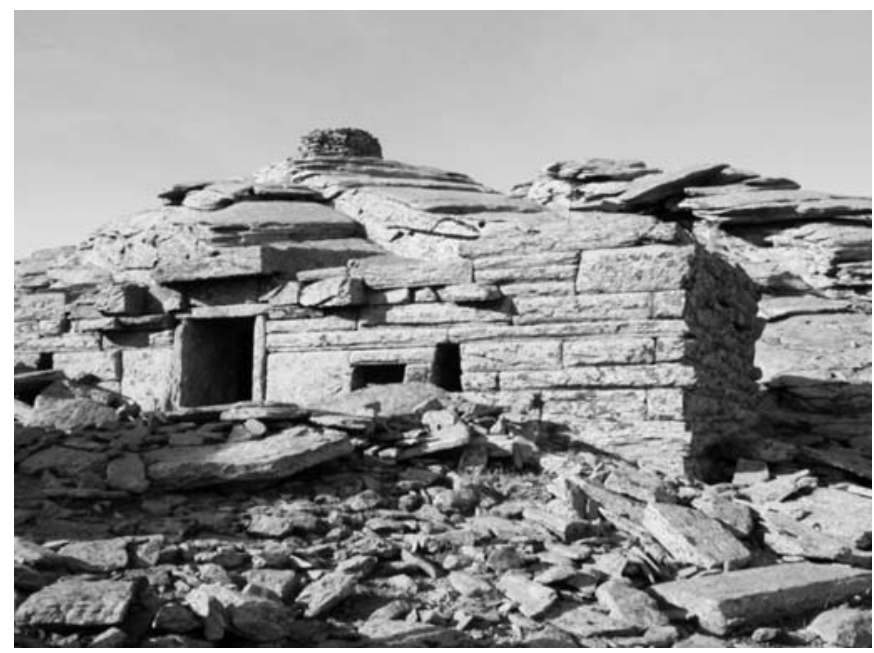

Fig. 1: The Mt. Óchi Drakóspito: External view.

\section{Historical data}

\subsection{Euboea Island}

Among the extant buildings being made of Karystía Líthos, the most imposing are the "drakóspita" (= dragon houses). That is the name given to some megalithic buildings (20 - 30 of them have been discovered to-date) mainly located in southern Euboea. The most important of them (Fig. 1) is found on the top of Mt. Óchi at an altitude of about 1400 m, overlooking the town of Karystos. Also, rather impressive are the 3 drakóspita near the town of Styra.

The Óchi "drakóspito" (= dragon house) is located on a small plateau formed between the twin tops of the mountain. It has been built with boulders and slabs quarried in the surrounding area. Those building elements have been shaped and they are perfectly matched without any binding material. The drakóspito walls are almost 1,50 m thick and its internal dimensions are about $(5 \times 10) \mathrm{m}$. The slab over the entrance measures $(4 \times 2 \times 0,30) \mathrm{m}$. This structure is thought to be a Dryopic temple built before $700 \mathrm{BC}$, while other views date its construction before the Trojan War $(\sim 1300 \mathrm{BC})$ or even during the Neolithic Age (i.e. before 3000 BC).

The drakóspita roofs are structured following the "ekphorikón" system. This structure demands precise calculations and considerable skill. It is achieved by placing an inwardly protruding row of slabs on one wall of the drakóspito, followed by a second row protruding more, and so on, until the last row meet the relevant row from the opposite wall. If the slabs' weight calculations are not adequate, the structure's centre of gravity will be shifted off the walls and the roof will collapse. To avoid this, other boulders have been used as counterbalancing weights over the slabs' part lying on the walls.

The slabs, the counterbalancing weights and most of the structure's boulders are of huge ("cyclopean") dimensions, and some of those elements weigh many tons.

Finally, near Aetos village (to the east of Karystos) there is an ancient quarry with big columns lying abandoned. Most of them are about $1.70 \mathrm{~m}$ in diameter and $13.50 \mathrm{~m}$ in height. 

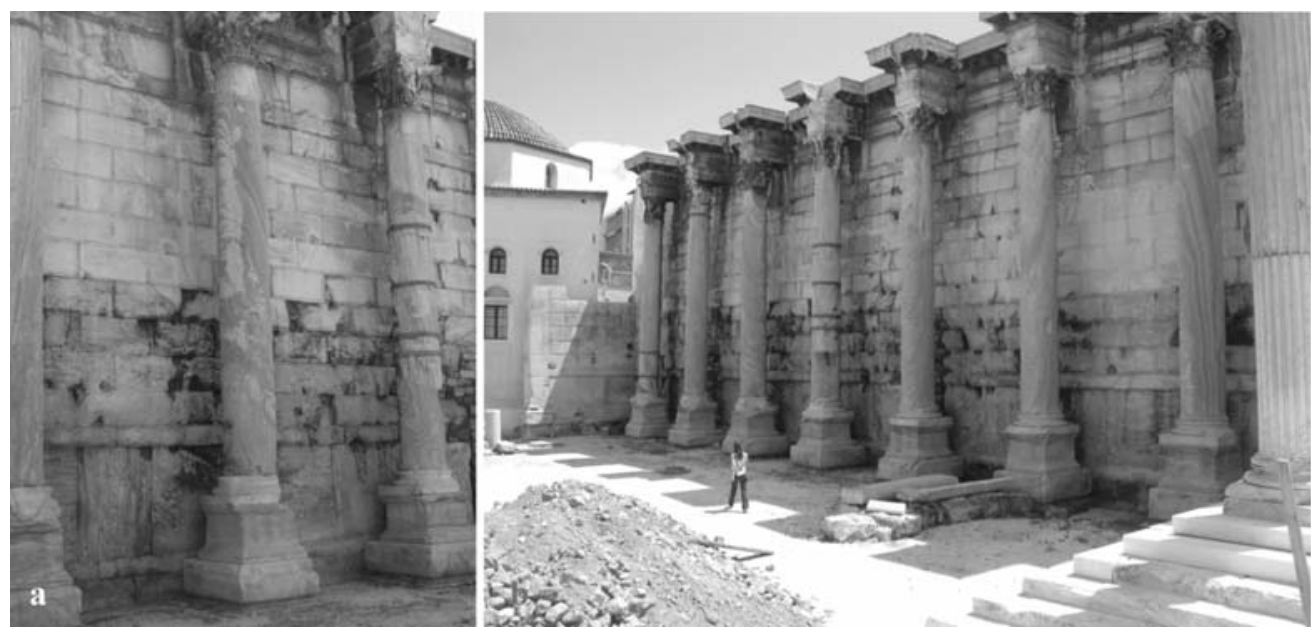

Fig. 2: The Library of Hadrianus: (a) Three of the columns (close view), (b) The NW wing of the façade propylon, with the seven extant columns.

\subsection{City of Athens}

An ancient monument of Athens, in the construction of which Karystía Líthos has been used, is the Library of Hadrianus (Fig. 2). It was built around $132 \mathrm{AD}$, during the reign of the Roman Emperor Hadrianus (117 - 138 AD), and takes up an orthogonal area of $(122 \times 82) \mathrm{m}$ in the northern part of the Roman Agora. This is a big rectangular structure with an open peristyle courtyard measuring about $(82 \times 60) \mathrm{m}$ and its perimeter was bordered by 100 columns $(22$ each on the east and the west side and 28 each on the north and the south one). The Library's façade is located on the west side of the building. The entrance, with a propylon of 4 Corinthian columns, was found in the middle of this western wall. The façade wall was decorated with 7 Corinthian columns on each side (i.e. the left and the right wing) of the entrance. The Library was partly destroyed during the Heruli raid (267 AD) and refurbished in the beginning of the 5th century AD. Today, a relatively small part of the façade is still standing (i.e. the NW wing) on Áreos Street, where the modern tourist may have the opportunity to admire the 7 imposing Corinthian columns made of Karystía Líthos.

\section{Laboratory testing}

\subsection{Mineralogical - petrographic study of Karystía Líthos (commercially “Karystos schists")}

The relevant geological survey has located two horizons whose thickness occasionally reaches 10 $15 \mathrm{~m}$, in which green ("cipollino") and brown to black marble alternations are observed. Karystos schists are quarried in these horizons.

Most of the quarries are located in the areas of Aghios Dimitrios, Melissonas, Stouppaeoi, Paradissi, Aktaion (Marmari Municipality) and Kalyvia, Grambias (Karystos Municipality). Out of a recorded quarrying area of $1800 \times 103 \mathrm{~m}^{2}$, where about 75 quarrying companies are active, the $850 \times 103 \mathrm{~m}^{2}$ are found in Aghios Dimitrios. The main Karystos schist types coming from the above areas are "Green-Grey" ( 49.5\%), "Grey-Black" $(\sim 48 \%)$ and "Brown" $(\sim 2.5 \%)$. The total production of all types reaches 170000 tpa. 
The following data were derived from the mineralogical - petrographic study (I.G.M.E., Mineralogy - Petrography Division) of slate samples:

- The material is the same in all the quarries and corresponds to different colour varieties of fine- to ultra fine-grained "cipollino marble" (the calcite crystals' size is $\sim 0,20 \mathrm{~mm}$ ) with a granoblastic - lepidoblastic fabric, whose main feature is dynamic metamorphism (the secondary fabric type is protomylonitic - mylonitic).

- In all quarries, alternating horizons of various thickness occur, mainly consisting of brownishblack, brown, brownish-green and light green cipollino marble always with a banded texture, while in some sites the marble also exhibits chestnut, orange, violet and emerald-green hues.

- The mineralogical composition of the cipollino marble is as follows:

- Calcite (main mineral), 83 - $93 \%$ wt

- Quartz, 1 - 6\% wt

- Albite, 1 - $4 \% \mathrm{wt}$

- Muscovite, 2 - $5.5 \% \mathrm{wt}$

- Chlorite, $1.5-5.5 \% \mathrm{wt}$

- Accessory minerals: titanite, leucoxene, rutile, epidote, glaucophane, biotite, tourmaline, pyrite, iron oxides / hydroxides, organic matter, each of them at very low content $(\leq 1 \%$ wt) and at various proportions.

- The colour of Karystos schists depends on their secondary and accessory minerals content. Thus, the brown or brownish-black varieties are characterized by a relatively increased organic matter and Ti-ferous materials content; the greenish ones by their marked muscovite and chlorite content; the chestnut ones by the presence of iron oxides / hydroxides; the violet contain glaucophane or Mn-ferous compounds etc.

- In some cases, layers consisting either of "common" marble or calc-mica schist are intercalated within the cipollino marble. The presence of those layers provides evidence on the composition of the initial sedimentary materials from which this marble was formed via metamorphism.

- All rocks found in the quarries have undergone dynamic metamorphism. This is evident mainly as folding tectonics, being responsible for the modification of the rocks' initial texture and fabric, as well as for the deformation of their mineralogical constituents (microfolds, cracks, cataclastic fabric formation etc.). According to the microscopic study, the material called "ágrio" in the quarry jargon exhibits mainly cataclastic fabric (protomylonitic or mylonitic), while the so-called "strimméno" is mainly microfolded.

- The schistosity of the cipollino marble and its ability to be readily separated into slabs, hence its exploitability, depend on three basic parameters: (a) the favourable lineation and layer orientation of the sheet-silicates (muscovite, chlorite); (b) the thickness and pureness of the foliaceous banded intercalations; (c) the tectonics.

The average chemical assay of an indicative sample of cipollino marble is given below (Table 1).

Table 1. Average chemical assay of cipollino marble (\% in dry substance) (*).

\begin{tabular}{|c|c|c|c|c|c|c|c|c|c|c|c|c|}
\hline & $\mathrm{SiO}_{2}$ & $\mathrm{Al}_{2} \mathrm{O}_{3}$ & $\mathrm{Fe}_{2} \mathrm{O}_{3}$ & $\mathrm{CaO}$ & $\mathrm{MgO}$ & $\mathrm{K}_{2} \mathrm{O}$ & $\mathrm{Na}_{2} \mathrm{O}$ & $\mathrm{MnO}$ & $\mathrm{Ti}$ & $\mathrm{Pb}$ & $\mathrm{Cr}$ & $\mathrm{LOI}$ \\
\hline Content & 7.40 & 1.75 & 1.15 & 47.00 & 0.65 & 0.33 & 0.27 & 0.10 & $<0.01$ & 0.02 & 0.01 & 40.00 \\
\hline
\end{tabular}

(*)I.G.M.E., Analytical Laboratories Division 


\subsection{Physical - mechanical properties}

The natural stone properties are classified into those characterizing the material, such as the apparent density, the open porosity, the water absorption etc., and those determining the suitability of the stone for various special uses, such as the compressive strength, the flexural strength, the dynamic modulus of elasticity, the effect of thermal and/or freeze-thaw cycles on its strength, the impact strength, the abrasion resistance, etc.

The determination of the above properties was based, in general, upon the test methods specified in Standard EN 12326-2 "Slate and stone products for discontinuous roofing and cladding - Part 2: Methods of test". Each of those properties is briefly outlined below.

\subsubsection{Apparent density, $\mathrm{kg} / \mathrm{m}^{3}$}

Apparent density is the ratio between the specimen's mass and its apparent volume (i.e. the volume of specimen's mass plus the volume of any included voids). It is connected to the structure's weight and provides information about the compactness of the material. The determination was based upon EN 12326-2, in combination with DIN 52102. Eighty specimens were employed.

\subsubsection{Open porosity, $\%$ vol}

Open porosity is the volume of the specimen's open voids (pores), as a percentage of its apparent volume. It is mainly connected to the external use of the material under moisture conditions and provides information about its compactness, strength and toughness. The determination was based upon EN 12326-2, in combination with DIN 52102. Eighty specimens were employed.

\subsubsection{Water absorption, \% wt}

Water absorption, a property directly related to open porosity, is the mass of water held within a saturated specimen, as a percentage of its mass. It is mainly connected to the external use of the material under moisture conditions and provides information about its compactness, strength and toughness. The determination was based upon EN 12326-2, in combination with DIN 52103. Eighty specimens were employed.

\subsubsection{Dynamic modulus of elasticity, GPa}

The dynamic modulus of elasticity, calculated during the flexural strength test, is a significant property when the slabs are going to be used in cladding and roofing. It gives an indication of the material's ability to resume its initial state after the removal of a potential mechanical stress. The determination was based upon EN 12326-2, in combination with DIN 52112. Forty specimens were employed.

\subsubsection{Compressive strength, MPa}

Compressive strength is the ratio between the load producing the breakage of the specimen and its cross-sectional area (perpendicular to the loading direction). It is connected to the static loading capacity of the material and provides evidence on its resistance to mechanical stresses. Standard EN 12326-2 does not provide for the compressive strength determination of slates, because due to their anisotropy (schistosity plains, etc.) the relevant results are not considered reliable. This test was performed only for reasons of comparison with other ornamental stones. The determination was based upon DIN 52105. Twenty-four specimens were employed. 


\subsubsection{Flexural strength, $\mathrm{MPa}$}

Flexural strength is the ratio between the bending moment producing the breakage of the specimen and the moment of resistance developed in it. It is connected to the dynamic loading capacity of the material and provides evidence on its resistance to mechanical stresses and contributes in selecting a stone appropriate for use in cladding, roofing, stairs and paving. The determination was based upon EN 12326-2, in combination with DIN 52112. Twenty-four specimens were employed.

\subsubsection{Flexural strength after freeze-thaw cycles, MPa}

The determination of flexural strength after freeze-thaw cycles, simulating the ageing of the material, is significant in determining its behaviour for external applications in moist and cold climates. The strength thus obtained is compared to that corresponding to specimens having not undergone freeze-thaw cycles. The determination was based upon EN 12326-2, in combination with DIN 52104 and DIN 52112. Forty specimens were employed.

\subsubsection{Flexural strength after thermal cycles, $\mathrm{MPa}$}

The determination of flexural strength after thermal cycles, simulating the ageing of the material, provides useful information on its behaviour when used externally in moist areas with significantly wide range of temperatures between day and night or between seasons. The strength thus obtained is compared to that corresponding to specimens having not undergone thermal cycles. The determination was based upon EN 12326-2, in combination with DIN 52204 and DIN 52112. Thirtyseven specimens were employed.

\subsubsection{Abrasion resistance - Böhme, $\mathrm{mm}$}

Abrasion resistance is the height loss of the specimen under abrasion on the appropriate apparatus. It is connected to the differential wear and the finishing ability of the material, being decisive for selecting a stone suitable for paving and stairs. The determination was based upon EN 12326-2, in combination with DIN 52108. Twenty-four specimens were employed.

\subsubsection{Impact strength, $\mathrm{cm}$}

Impact strength is the minimum height from which a steel ball falling on a slab of a given material causes its breakage. It is connected to the instantaneous dynamic loading capacity of the material, being significant in selecting a stone suitable for paving and stairs. The determination was based upon EN 12326-2, in combination with Italian Standard UNI-U 32.07.248.0. Twenty-four specimens were employed.

\section{Statistical analysis of the tests results}

\subsection{Overview}

The considerable number of measurements collected, made it possible to statistically evaluate them in order to calculate the relative confidence intervals for the values of the physical - mechanical properties that were determined.

The "classical" way was followed for this calculation, i.e. the Normal distribution (z-tests) has been employed for large samples $\left(\mathrm{N}_{\mathrm{x}} \geq 30\right)$ and the Student t-distribution (t-tests) for small samples $\left(\mathrm{N}_{\mathrm{x}}<30\right)$. All the necessary calculations were performed by means of Microsoft ${ }^{\circledR}$ Excel. 


\subsection{Statistical analysis}

\subsubsection{Apparent density}

Sample size $\mathbf{N}_{\mathbf{x}}=80$, Mean $\overline{\mathbf{x}}=2716 \mathrm{~kg} / \mathrm{m}^{3}$, Standard deviation $\hat{\mathbf{s}}_{\mathbf{x}}=16 \mathrm{~kg} / \mathrm{m}^{3}$

Confidence intervals for the population mean $\boldsymbol{\mu}_{\mathbf{x}}$ (z-test):

At a $90 \%$ confidence level ${ }^{(1)} \rightarrow \mathbf{2 7 1 3 . 1} \mathbf{~ k g} / \mathrm{m}^{3}<\boldsymbol{\mu}_{\mathrm{x}}<\mathbf{2 7 1 8 . 9} \mathrm{kg} / \mathrm{m}^{3}$

At a $95 \%$ confidence level $\rightarrow 2712.6 \mathrm{~kg} / \mathrm{m}^{3}<\boldsymbol{\mu}_{\mathrm{x}}<2719.4 \mathrm{~kg} / \mathrm{m}^{3}$

At a $99 \%$ confidence level $\rightarrow \mathbf{2 7 1 1 . 5} \mathbf{~ k g} / \mathrm{m}^{3}<\boldsymbol{\mu}_{\mathrm{x}}<2720.5 \mathrm{~kg} / \mathrm{m}^{3}$

Those data show that Karystos schists are sufficiently compact and they do not exhibit significant variation in the values of their apparent density.

\subsubsection{Open porosity}

Sample size $\mathbf{N}_{\mathbf{x}}=80$, Mean $\overline{\mathbf{x}}=0.20 \%$ vol, Standard deviation $\hat{\mathbf{s}}_{\mathbf{x}}=0.11 \%$ vol

Confidence intervals for the population mean $\boldsymbol{\mu}_{\mathbf{x}}$ (z-test):

At a $90 \%$ confidence level $\rightarrow \mathbf{0 . 1 8 0} \%$ vol $<\boldsymbol{\mu}_{\mathbf{x}}<\mathbf{0 . 2 2 0} \%$ vol

At a $95 \%$ confidence level $\rightarrow \mathbf{0 . 1 7 6} \%$ vol $<\boldsymbol{\mu}_{\mathbf{x}}<\mathbf{0 . 2 2 4} \%$ vol

At a $99 \%$ confidence level $\rightarrow \mathbf{0 . 1 6 9 \%}$ vol $<\boldsymbol{\mu}_{\mathbf{x}}<\mathbf{0 . 2 3 1} \%$ vol

Open porosity of the Karystos schists is relatively low, thus rendering them sufficiently tough.

\subsubsection{Water absorption}

Sample size $\mathbf{N}_{\mathbf{x}}=80$, Mean $\overline{\mathbf{x}}=0,08 \%$ wt, Standard deviation $\hat{\mathbf{s}}_{\mathbf{x}}=0.04 \% \mathrm{wt}$

Confidence intervals for the population mean $\boldsymbol{\mu}_{\mathbf{x}}$ (z-test):

At a $90 \%$ confidence level $\rightarrow \mathbf{0 . 0 7 2} \%$ wt $<\boldsymbol{\mu}_{\mathbf{x}}<\mathbf{0 . 0 8 8} \%$ wt

At a $95 \%$ confidence level $\rightarrow \mathbf{0 . 0 7 0} \%$ wt $<\boldsymbol{\mu}_{\mathbf{x}}<\mathbf{0 . 0 9 0} \%$ wt

At a $99 \%$ confidence level $\rightarrow \mathbf{0 . 0 6 7 \%}$ wt $<\boldsymbol{\mu}_{\mathbf{x}}<\mathbf{0 . 0 9 3} \%$ wt

The toughness of the Karystos schists is also justified by their relatively low water absorption.

\subsubsection{Dynamic modulus of elasticity}

Sample size $\mathbf{N}_{\mathbf{x}}=40$, Mean $\overline{\mathbf{x}}=25.60 \mathrm{GPa}$, Standard deviation $\hat{\mathbf{s}}_{\mathbf{x}}=10.57 \mathrm{GPa}$

Confidence intervals for the population mean $\boldsymbol{\mu}_{\mathbf{x}}$ (z-test):

At a $90 \%$ confidence level $\rightarrow \mathbf{2 2 . 8 5}$ GPa $<\boldsymbol{\mu}_{\mathbf{x}}<28.35$ GPa

At a $95 \%$ confidence level $\rightarrow \mathbf{2 2 . 3 2} \mathbf{G P a}<\boldsymbol{\mu}_{\mathrm{x}}<28.88 \mathrm{GPa}$

At a $99 \%$ confidence level $\rightarrow \mathbf{2 1 . 2 9}$ GPa $<\mu_{\mathrm{x}}<29.91 \mathrm{GPa}$

The dynamic modulus of elasticity of the Karystos schists is relatively high and justifies their satisfactory elastic mechanical behaviour.

(1) The term "...at an $\boldsymbol{\varepsilon} \%$ confidence level" practically means that there is an $\boldsymbol{\varepsilon} \%$ probability for the mean $\boldsymbol{\mu}_{\mathrm{x}}$ of the normal population, from which the certain sample has been drawn, to be included in the relative confidence interval. Furthermore, if $\mathbf{1 0 0}$ random independent samples would be drawn from a normal population $\left(\mathrm{x}_{1}, \mathrm{x}_{2}\right.$, $\ldots, \mathrm{x}_{\mathrm{n}}$ ), then $\boldsymbol{\varepsilon}$ out of the $\mathbf{1 0 0}$ relevant (i.e. at an $\boldsymbol{\varepsilon} \%$ confidence level) confidence intervals $\mathbf{a}_{\mathbf{i}}<\boldsymbol{\mu}_{\mathbf{x}}<\mathbf{b}_{\mathbf{i}}(\mathrm{i}=1$ to 100 ) being calculated from the above samples will contain the mean $\boldsymbol{\mu}_{\mathbf{x}}$ of the population $\left(\mathrm{x}_{1}, \mathrm{x}_{2}, \ldots, \mathrm{x}_{\mathrm{n}}\right)$. 


\subsubsection{Compressive strength}

Sample size $\mathbf{N}_{\mathbf{x}}=24$, Mean $\overline{\mathbf{x}}=52.60 \mathrm{MPa}$, Standard deviation $\hat{\mathbf{s}}_{\mathbf{x}}=16.06 \mathrm{MPa}$

Confidence intervals for the population mean $\boldsymbol{\mu}_{\mathbf{x}}$ (t-test):

At a $90 \%$ confidence level $\rightarrow \mathbf{4 6 . 9 8} \mathrm{MPa}<\boldsymbol{\mu}_{\mathrm{x}}<\mathbf{5 8 . 2 2} \mathrm{MPa}$

At a $95 \%$ confidence level $\rightarrow \mathbf{4 5 . 8 2} \mathrm{MPa}<\boldsymbol{\mu}_{\mathrm{x}}<\mathbf{5 9 . 3 8} \mathrm{MPa}$

At a $99 \%$ confidence level $\rightarrow \mathbf{4 3 . 4 0} \mathbf{M P a}<\boldsymbol{\mu}_{\mathrm{x}}<\mathbf{6 1 . 8 0} \mathbf{M P a}$

Due to their schistosity, the compressive strength of the Karystos schists is expectedly lower than that presented by other more homogeneous stones. Nevertheless, the measured values are satisfactory.

\subsubsection{Flexural strength}

Sample size $\mathbf{N}_{\mathbf{x}}=24$, Mean $\overline{\mathbf{x}}=24.38 \mathrm{MPa}$, Standard deviation $\hat{\mathbf{s}}_{\mathbf{x}}=5.99 \mathrm{MPa}$

Confidence intervals for the population mean $\boldsymbol{\mu}_{\mathrm{x}}(\mathrm{t}$-test):

At a 90\% confidence level $\rightarrow 22.29 \mathrm{MPa}<\boldsymbol{\mu}_{\mathrm{x}}<26.47 \mathrm{MPa}$

At a 95\% confidence level $\rightarrow 21.85 \mathrm{MPa}<\boldsymbol{\mu}_{\mathrm{x}}<26.91 \mathrm{MPa}$

At a $99 \%$ confidence level $\rightarrow \mathbf{2 0 . 9 5} \mathrm{MPa}<\boldsymbol{\mu}_{\mathrm{x}}<27.81 \mathrm{MPa}$

Flexural strength of the Karystos schists is high and the measured values do not exhibit significant variation. The very satisfactory mechanical behaviour of Karystos schists in roofing, flooring, etc. is due to this property.

\subsubsection{Flexural strength after freeze-thaw cycles}

Sample size $\mathbf{N}_{\mathbf{x}}=40$, Mean $\overline{\mathbf{x}}=18.69 \mathrm{MPa}$, Standard deviation $\hat{\mathbf{s}}_{\mathbf{x}}=4.86 \mathrm{MPa}$

Confidence intervals for the population mean $\boldsymbol{\mu}_{\mathbf{x}}$ (z-test):

At a $90 \%$ confidence level $\rightarrow \mathbf{1 7 . 4 3} \mathrm{MPa}<\boldsymbol{\mu}_{\mathrm{x}}<\mathbf{1 9 . 9 5} \mathrm{MPa}$

At a $95 \%$ confidence level $\rightarrow \mathbf{1 7 . 1 9} \mathrm{MPa}<\boldsymbol{\mu}_{\mathrm{x}}<20.19 \mathrm{MPa}$

At a $99 \%$ confidence level $\rightarrow \mathbf{1 6 . 7 1} \mathrm{MPa}<\boldsymbol{\mu}_{\mathrm{x}}<20.67 \mathrm{MPa}$

Though the freeze-thaw cycles test lowers slightly the flexural strength of the Karystos schists (see item 4.2.6.), it still remains sufficiently high and the measured values do not exhibit significant variation. In addition, the specimens having undergone the test do not present any deterioration or alterations. Consequently, the schists are suitable for external applications, particularly in moderately cold and moist climates as in most parts of Hellas.

\subsubsection{Flexural strength after thermal cycles}

Sample size $\mathbf{N}_{\mathbf{x}}=37$, Mean $\overline{\mathbf{x}}=22.98 \mathrm{MPa}$, Standard deviation $\hat{\mathbf{s}}_{\mathbf{x}}=7.26 \mathrm{MPa}$

Confidence intervals for the population mean $\boldsymbol{\mu}_{\mathrm{x}}$ (z-test):

At a $90 \%$ confidence level $\rightarrow 21.02 \mathrm{MPa}<\boldsymbol{\mu}_{\mathrm{x}}<24.94 \mathrm{MPa}$

At a $95 \%$ confidence level $\rightarrow 20.64 \mathrm{MPa}<\boldsymbol{\mu}_{\mathrm{x}}<25.32 \mathrm{MPa}$

At a $99 \%$ confidence level $\rightarrow \mathbf{1 9 . 9 1} \mathrm{MPa}<\boldsymbol{\mu}_{\mathrm{x}}<26.05 \mathrm{MPa}$

The effect of the thermal cycles test on the flexural strength of the Karystos schists is negligible (see item 4.2.6.), while the measured values do not exhibit significant variation. In addition, the specimens having undergone the test do not present any deterioration or alterations. Consequently, the schists are suitable for external applications, even in moist areas where the temperature variations are considerable. 
Table 2: Confidence intervals for the mean $\mu_{\mathrm{x}}$ of each population, at given confidence levels $\varepsilon$.

\begin{tabular}{|c|c|c|c|}
\hline \multirow{2}{*}{$\begin{array}{l}\text { PHYSICAL - MECHANICAL } \\
\text { PROPERTIES }\end{array}$} & \multicolumn{3}{|c|}{ CONFIDENCE INTERVALS } \\
\hline & $\varepsilon=90 \%$ & $\varepsilon=95 \%$ & $\varepsilon=99 \%$ \\
\hline Apparent density, $\mathrm{kg} / \mathrm{m}^{3}$ & $2713.1<\boldsymbol{\mu}_{\mathrm{x}}<2718.9$ & $2712.6<\boldsymbol{\mu}_{\mathrm{x}}<2719.4$ & $2711.5<\boldsymbol{\mu}_{\mathrm{x}}<2720.5$ \\
\hline Open porosity, $\%$ vol & $0.180<\boldsymbol{\mu}_{\mathbf{x}}<0.220$ & $0.176<\boldsymbol{\mu}_{\mathbf{x}}<0.224$ & $0.169<\boldsymbol{\mu}_{\mathrm{x}}<0.231$ \\
\hline Water absorption, \% wt & $0.072<\boldsymbol{\mu}_{\mathrm{x}}=<0.088$ & $0.070<\boldsymbol{\mu}_{\mathbf{x}}<0.090$ & $0.067<\boldsymbol{\mu}_{\mathrm{x}}<0.093$ \\
\hline Dynamic modulus of elasticity, GPa & $22.85<\boldsymbol{\mu}_{\mathbf{x}}<28.35$ & $22.32<\boldsymbol{\mu}_{\mathbf{x}}<28.88$ & $21.29<\boldsymbol{\mu}_{\mathbf{x}}<29.91$ \\
\hline Compressive strength, $\mathrm{MPa}$ & $46.98<\boldsymbol{\mu}_{\mathbf{x}}<58.22$ & $45.82<\boldsymbol{\mu}_{\mathrm{x}}<59.38$ & $43.40<\boldsymbol{\mu}_{\mathrm{x}}<61.80$ \\
\hline Flexural strength, $\mathrm{MPa}$ & $22.29<\boldsymbol{\mu}_{\mathbf{x}}<26.47$ & $21.85<\boldsymbol{\mu}_{\mathrm{x}}<26.91$ & $20.95<\boldsymbol{\mu}_{\mathrm{x}}<27.81$ \\
\hline $\begin{array}{l}\text { Flexural strength after freeze-thaw cy- } \\
\text { cles, } \mathrm{MPa}\end{array}$ & $17.43<\boldsymbol{\mu}_{\mathrm{x}}<19.95$ & $17.19<\boldsymbol{\mu}_{\mathbf{x}}<20.19$ & $16.71<\boldsymbol{\mu}_{\mathrm{x}}<20.67$ \\
\hline $\begin{array}{l}\text { Flexural strength after thermal } \\
\text { cycles, } \mathrm{MPa}\end{array}$ & $21.02<\boldsymbol{\mu}_{\mathrm{x}}<24.94$ & $20.64<\boldsymbol{\mu}_{\mathbf{x}}<25.32$ & $19.91<\boldsymbol{\mu}_{\mathbf{x}}<26.05$ \\
\hline Abrasion resistance - Böhme, mm & $2.31<\boldsymbol{\mu}_{\mathrm{x}}<2.77$ & $2.27<\boldsymbol{\mu}_{\mathrm{x}}<2.81$ & $2.17<\boldsymbol{\mu}_{\mathrm{x}}<2.91$ \\
\hline Impact strength, cm & $52.6<\boldsymbol{\mu}_{\mathrm{x}}<59.4$ & $51.9<\boldsymbol{\mu}_{\mathrm{x}}<60.1$ & $50.4<\boldsymbol{\mu}_{\mathrm{x}}<61.6$ \\
\hline
\end{tabular}

\subsubsection{Abrasion resistance - Böhme}

Sample size $\mathbf{N}_{\mathbf{x}}=24$, Mean $\overline{\mathbf{x}}=2.54 \mathrm{~mm}$, Standard deviation $\hat{\mathbf{s}}_{\mathbf{x}}=0.65 \mathrm{~mm}$

Confidence intervals for the population mean $\boldsymbol{\mu}_{\mathbf{x}}(\mathrm{t}$-test):

At a $90 \%$ confidence level $\rightarrow \mathbf{2 . 3 1} \mathbf{m m}<\boldsymbol{\mu}_{\mathrm{x}}<\mathbf{2 . 7 7} \mathbf{~ m m}$

At a $95 \%$ confidence level $\rightarrow \mathbf{2 . 2 7} \mathbf{m m}<\boldsymbol{\mu}_{\mathrm{x}}<\mathbf{2 . 8 1} \mathbf{m m}$

At a $99 \%$ confidence level $\rightarrow \mathbf{2 . 1 7} \mathbf{m m}<\boldsymbol{\mu}_{\mathrm{x}}<2.91 \mathrm{~mm}$

Expressed as the (relatively low, in this case) average thickness of the material's layer abraded from each specimen during the relevant test, the abrasion resistance of the Karystos schists is high and justifies their endurance and appearance stability. The measured values do not exhibit any significant variation.

\subsubsection{Impact strength}

Sample size $\mathbf{N}_{\mathbf{x}}=24$, Mean $\overline{\mathbf{x}}=56 \mathrm{~cm}$, Standard deviation $\hat{\mathbf{s}}_{\mathbf{x}}=10 \mathrm{~cm}$

Confidence intervals for the population mean $\boldsymbol{\mu}_{\mathbf{x}}(\mathrm{t}$-test):

At a $90 \%$ confidence level $\rightarrow \mathbf{5 2 . 6} \mathbf{~ c m}<\boldsymbol{\mu}_{\mathbf{x}}<\mathbf{5 9 . 4} \mathbf{~ c m}$

At a $95 \%$ confidence level $\rightarrow \mathbf{5 1 . 9} \mathbf{~ c m ~}<\boldsymbol{\mu}_{\mathrm{x}}<\mathbf{6 0 . 1} \mathbf{~ c m}$

At a $99 \%$ confidence level $\rightarrow \mathbf{5 0 . 4} \mathbf{~ c m}<\boldsymbol{\mu}_{\mathrm{x}}<\mathbf{6 1 . 6} \mathbf{c m}$

Impact strength of the Karystos schists is relatively high and justifies their endurance under significant instantaneous mechanical stresses. The measured values do not exhibit any significant variation.

All the above confidence intervals for the population mean $\boldsymbol{\mu}_{\mathbf{x}}$ of each physical - mechanical property are summarized in Table 2 , according to their corresponding confidence level $\boldsymbol{\varepsilon}$.

\section{Conclusions}

Karystía Líthos has been widely used since archaic times in the construction of columns, monuments and other buildings of colossal ("cyclopean") dimensions for decorative, ritualistic or other 
practical purposes. Those constructions date before $700 \mathrm{BC}$ or before the Trojan War $(\sim 1300 \mathrm{BC})$ or even as early as the Neolithic Age (> $3000 \mathrm{BC})$.

Geological survey has located two horizons whose thickness occasionally reaches $10-15 \mathrm{~m}$, in which green and brown to black marble alternations are observed. Karystos schists are quarried in these horizons. About 75 quarrying companies are active in the region. Out of a recorded quarrying area of $1800 \times 103 \mathrm{~m}^{2}$, the $50 \%$ is found in Aghios Dimitrios. The main Karystos schist types quarried are "Green-Grey", "GreyBlack" and, at a lesser extent, "Brown". The total production is about 170000 tpa.

All the slate samples examined correspond to a special marble variety (cipollino marble). Their main mineralogical constituent is calcite $(85-95 \% \mathrm{wt})$, while the secondary minerals are muscovite + chlorite + quartz + albite $(2-5 \%$ wt each). The accessory minerals are epidote, titanite, oxidized pyrite, iron oxides/ hydroxides, tourmaline, organic matter and Mn-ferous compounds. The colour of Karystos schists depends on their secondary and accessory minerals content.

All rocks found in the quarries have undergone dynamic metamorphism. This is evident mainly as folding tectonics, being responsible for the disturbance of the rocks texture and fabric, as well as for the deformation of their mineralogical constituents (microfolds, cracks, cataclastic fabric formation etc.).

The exploitability of cipollino marble relates with its schistosity and its ability to be readily separated into slabs, depending on three basic parameters: (a) the favourable lineation and layer orientation of the sheet-silicates (muscovite, chlorite); (b) the thickness and pureness of the foliaceous banded intercalations; (c) the tectonics.

Karystos schists are compact and tough. They present low water absorption and open porosity.

The values of mechanical properties determined for Karystos schists are much higher than the minimum acceptable for ornamental stones.

Abrasion resistance and impact strength of Karystos schists justify their endurance.

The absence of any deterioration or alterations from the Karystos schists specimens after "environmental" testing (freeze-thaw and thermal cycles) and the slight to negligible effect observed on their flexural strength, render Karystos schists suitable for external applications under various climatic conditions.

The physical - mechanical properties of Karystía Líthos (commercially "Karystos schists"), on which its endurance through time and under mechanical stresses is depending, as well as its aesthetics resulting from its mineralogical composition, render it an attractive structural ornamental stone with a wide range of applications to-date, thus confirming and justifying the timelessness in its use.

\section{References}

Himmelblau, D. M. 1970. Process Analysis by Statistical Methods, Sterling Swift Publishing Co., Texas, 1970.

Laskaridis, K., Papaioannou, N., Kousseris, I. 2002. Mapping and Recording of the Karystos Schists Exploitable Reserves, Final Report, I.G.M.E., LITHOS Laboratory, Athens, May 2002 (in Hellenic).

Mastrapas, A. 1999. Topography of the Ancient Athens monuments, Kardamitsas Editions, 2nd Ed. Updated, Athens, 1999 (Historical data in "2.2. City of Athens" - in Hellenic).

Patronis, M. 2002. Application of Statistical Analysis Methods for Evaluating the Physical Mechanical Properties Determination Tests Results of Karystos Schists, I.G.M.E., LITHOS Laboratory, Athens, May 2002 (in Hellenic).

Spiegel, M. R. (Author), Lindstrom, D. P. (Editor) 2000. Statistics, Schaum's Easy Outlines, McGraw Hill, 2000.

Web Site. http://www.galaxy.gr/drakospita-01.htm (Historical data in "2.1. Euboea Island" - in Hellenic). 